American Journal of Pharmaceutical Education 2016; 80 (9) Article 146.

\title{
STATEMENT
}

\section{Academic Freedom Should Be Redefined: Point and Counterpoint}

\author{
Tonja M. Woods, PharmD, ${ }^{a}$ W. Renee' Acosta, MS, BS Pharm, ${ }^{b}$ Eunice P. Chung, PharmD, ${ }^{\mathrm{c}}$ \\ Arthur G. Cox, PhD, ${ }^{\mathrm{d}}$ George A. Garcia, PhD, ${ }^{\mathrm{e}}$ Jamie Ridley Klucken, PharmD, MBA, ${ }^{\mathrm{f}}$ \\ Marie Chisholm-Burns, PharmD, MPH, $\mathrm{MBA}^{\mathrm{g}}$ \\ ${ }^{\text {a }}$ The University of Wyoming, Laramie, Wyoming \\ ${ }^{b}$ The University of Texas, Austin, Texas \\ ${ }^{c}$ Western University of Health Sciences, Pomona, California \\ ${ }^{\mathrm{d}}$ South University, Savannah, Georgia \\ e The University of Michigan, Ann Arbor, Michigan \\ ${ }^{\mathrm{f}}$ Shenandoah University, Ashburn, Virginia \\ ${ }^{\mathrm{g}}$ The University of Tennessee Health Science Center, Memphis, Knoxville, and Nashville, Tennessee \\ Submitted December 10, 2015; accepted February 3, 2016; published November 25, 2016.
}

As part of the 2014-15 Academic Leadership Fellows Program, the cohort teams presented debates on topics relevant to academic pharmacy at a public forum during the 2015 American Association of Colleges of Pharmacy Interim Meeting. The topic of one of the debates was "Academic Freedom Should Be Redefined." The "point" of the debate focused on important issues such as the fundamental definition of academic freedom as it was written in the 1940 American Association of University Professors' Statement and the need for redefinition as a consequence of many misunderstandings and misinterpretations that have arisen over time. The "counterpoint" received the greatest support, and it asserted that redefinition is not necessary, but rather the need is to clearly articulate the intended meaning of academic freedom through education, discussion, and by not supporting inappropriate behaviors in the name of "academic freedom." Reinforced clarity and operational guidance from the academy and academic institutions may add further clarification and may be the best approach to address the concerns related to academic freedom.

Keywords: academic freedom, pharmacy, academic pharmacy, debate

\section{INTRODUCTION}

Academic freedom gives the professoriate the privilege to a free search for truth and knowledge and the right to impart those truths and knowledge to others, including students, the academy, and the general public, unfettered by political or ideological pressure. The protection of academic freedom did not exist in the early 1900s. Economist Edward Ross was fired from Stanford University in 1901 because his position on particular issues (eg, the gold standard) angered the cofounder of the university, Jane L. Stanford. ${ }^{1}$ During the McCarthy era, many professors were sanctioned or fired for presumed Communist sympathies. $^{2}$

The basic principles of the American Association of University Professors' (AAUP) 1940 Statement of Principles on Academic Freedom and Tenure assert that there

Corresponding Author: Tonja M. Woods, The University of Wyoming School of Pharmacy, 1000 E. University Ave., Dept. 3375, Laramie, WY 82071. Tel: 307-766-2550. Fax: 307-766-2953. E-mail: tmwoods@uwyo.edu is a clear and compelling societal benefit to academic freedom. ${ }^{3,4}$ This statement was coauthored by the Association of American Colleges and Universities (AACU) and endorsed by over 200 academic societies and associations. Member institutions of the AACU are therefore obligated to adhere to the principles delineated in the statement. The legally binding nature of these principles for public institutions has been repeatedly supported by the US Supreme Court, which defined academic freedom as "a special concern of the First Amendment which does not tolerate laws that cast a pall of orthodoxy over the classroom" (Keyishian v Board of Regents, 385 US 589 [1967] and reviewed by Van Alstyne ${ }^{5}$ ). Private colleges and universities are not governmental entities; therefore, the main source of legal protection for academic freedom at private colleges and universities is their own handbooks, policies, and faculty contracts, rather than the First Amendment.

The privilege of academic freedom requires faculty members to impart those truths and knowledge responsibly. Academic freedom is both an individual right and 


\section{American Journal of Pharmaceutical Education 2016; 80 (9) Article 146.}

a collective responsibility. ${ }^{6}$ In exercising academic freedom in teaching, the decisions of the collective may and in many cases must prevail over the dissenting position of an individual. ${ }^{6}$ The conflict between the academic freedom of the individual teacher and the that of the collective faculty raises the question of whether the overall definition of academic freedom should be reexamined and revised to account for societal changes in the academy over time.

A debate held during the 2014-15 Academic Leadership Fellows Program (ALFP) discussed whether "Academic Freedom Should Be Redefined." The authors chose the topic because the AAUP 1940 Statement has been widely misunderstood and misinterpreted. Also, they felt this subject would be not only an interesting topic for debate and discussion but also one that would have great significance to academic pharmacy.

The 1940 Statement identifies 3 fundamental principles of academic freedom which contend that college and university teachers are entitled to full freedom in research and in the publication of the results, and freedom in the classroom in discussing their subject, and should be free from institutional censorship or discipline when speaking or writing as private citizens. ${ }^{3}$

Additionally, the Statement was based on the premise that "institutions of higher education are conducted for the common good and not to further the interest of the individual teacher or the institution as a whole." ${ }^{3}$ Furthermore, academic freedom derives from the simple principle that "the common good depends upon the free search for truth and its free exposition.",3

\section{METHODS}

The American Association of College of Pharmacy (AACP), changed the direction for scholarship requirements for the 2014-15 ALFP cohort and instructed cohort teams to choose a topic to research and present as a debate at the AACP Interim Meeting. This paper provides a summary of the debate on academic freedom presented by one of the teams at the AACP Interim Meeting on February 6, 2015, in Austin, Texas.

The team selected the topic of academic freedom because it is a timely topic, there is little published on it in the pharmacy literature, and it is pertinent across the academy regardless of institutional differences in funding sources (eg, private or public), college/university size, discipline, and administrative and faculty structure. A literature search (Medline, PubMed, and Google Scholar) was conducted using the term "academic freedom." References were reviewed and discussed, and only those most relevant to the debate were selected. A targeted portion of the literature was selected to support each side of the focused debate. Three team members debated "for redefining" academic freedom, 3 team members debated "against redefining" academic freedom, and 1 team member served as the team facilitator.

\section{Point: Case for the Redefinition of Academic Freedom}

The intended purpose of the 1940 Statement of Academic Freedom is still valid today; however, several key points need to be brought into focus considering the many misunderstandings and misinterpretations of the definition and application. Pertinent points to consider in developing a more specific and comprehensive definition of academic freedom include, but are not limited to: full freedom vs freedom in responsibility to perform one's job duties; challenges of professional degree programs; modernization of educational environment; and increasing ratio of nontenured to tenured faculty members.

Some academicians believe academic freedom is the poetic license to do whatever they want, rather than the freedom to do their jobs and fulfill their responsibilities. Of course, faculty members should have the freedom to teach, research, and publish in the "search of truth." 3 This being said, they must also remember that while the scope of academic freedom may be broad, it is neither unlimited nor an absolute freedom from responsibilities or accountabilities and carries with it duties correlative with rights. ${ }^{3}$ Academic freedom therefore should be more specifically defined to reduce ambiguity and eliminate the support of interpretations of freedom to not participate in work assigned or reject performance expectations.

Professional degree programs like pharmacy present certain issues beyond that of freedom for the individual faculty member, namely programmatic challenges and regulations. To maintain accreditation compliance, institutions must ensure students meet program requirements, achieve competencies, acquire knowledge for pharmacy licensure, and exhibit professionalism, as well as obtain the necessary skills to adequately serve the public. Many other degree programs are not held to these standards. Another standard expectation of institutions is that courses taught by multiple instructors (a common occurrence in the pharmacy curriculum) should be operationalized and conducted with consensus. Once established, individual faculty members are expected not to deviate from agreed upon pedagogical methods and educational content or use "academic freedom" as a justification to not fulfill responsibilities or performance expectations, which may seem to prohibit faculty members from exercising their academic freedom. However, academic freedom does not protect individual faculty members when they violate policies, standards, practices or the direction 


\section{American Journal of Pharmaceutical Education 2016; 80 (9) Article 146.}

set for the greater good. Further definition of academic freedom should clearly state what academic freedom is and is not.

The economics of education has changed dramatically, especially in the past 2 decades. The academic freedom statement does not adequately reflect the current economic educational climate or contemporary teaching environments, which is another reason why a clearer interpretation and modernized definition are needed. Even since the interpretive statement was added in 1970 and additional comments were added in 1999 that discuss issues related to controversial teaching, teaching loads, and the need for developing a written contract with terms and conditions of appointment and employment, substantial changes have occurred. ${ }^{3,7}$ These changes include, but are not limited to, the explosion of technology used in teaching (eg, online teaching/distance learning), advent of social media blurring the boundaries of social and professional life, increasing number of nontraditional students, geographical migration of students, demand for greater return on investment, organizational redirection, and the general public's questioning of the value of postsecondary education given its cost. ${ }^{3,7,8}$

Perhaps one of the most profound changes in the academy is the increasing ratio of nontenured to tenured faculty members. Despite this shift, academic freedom has traditionally been and continues to be tied to the tenure system. However, the realities of the current academic landscape differ substantially from those that perpetuated this traditional view, which is yet another reason for redefining academic freedom. Faculty members who teach in a contingent manner, such as part-time instructors, nontenure faculty members, and adjunct volunteer faculty members comprise at least $70 \%$ of the university professoriate population. ${ }^{9}$ The 1940 Statement suggests that the academic freedom of those who are not full-time faculty members and/or those who are not in tenure-track positions are not protected, as it states "the concept of 'fulltime instructor or a higher rank' includes any person who teaches a full time load regardless of a specific title." 3,4 The question that begs to be asked is whether academic freedom applies only to full-time or tenure-eligible (or tenured) faculty members. Academic freedom should be a routine guarantee for any purposeful academic endeavor rather than a badge of merit awarded only to those who exist in a full-time position or, more specifically, a fulltime faculty member in a tenure-granting institution. Denying academic freedom to instructors without full-time appointments could imply that they do not have anything to say that is important enough to merit the protection of academic freedom. Regardless of the issues relating to tenure, a simple examination of the current definition of academic freedom reveals that it is so broad and vague that it is subject to too many interpretations and applications.

\section{Counterpoint: Case for Not Redefining Academic Freedom}

The AAUP 1940 Statement of Principles on Academic Freedom and Tenure has withstood the test of time and is accepted as the "general norm of academic practice in the United States." It is not necessary to redefine the statement, which often creates more confusion relative to the intended meaning of the original statement. What is necessary, however, is to clearly articulate its intended meaning through education and discussion, and by not supporting inappropriate behaviors in the name of "academic freedom."

According to the 1940 Statement, academic freedom is "fundamental to the advancement of truth." ${ }^{3}$ It is also "fundamental for the protection of the rights of the teacher in teaching and of the student to freedom in learning." 3 As described in the Introduction, academic freedom has been articulated as 3 basic principles: freedom to research and publish within one's area of expertise, freedom to teach within the assigned subject area, and freedom from censorship. ${ }^{3}$ Academic freedom does not entitle faculty members to engage in research endeavors outside their specialty area in order to pursue a personal agenda or to introduce into their classroom discussion issues (controversial or not) that are not relevant to their subject. While faculty members are free to speak and write as citizens, they must remain cognizant that the public may judge their profession as well as their institution based upon what they say, write and facilitate by their actions or the actions of others.

The 3 basic principles of academic freedom can be summarized as the freedom for a faculty member to "do his or her job." In many professions, such as pharmacy, other health care professions, business, engineering, etc, a systematic approach to success requires following policies and procedures amid a construct of expectations. When those expectations are not met, or policies are violated, consequences ensue. In striking parallel, a review of court cases relating to academic freedom revealed that faculty members have not been supported for "not doing their job" according to institutional policies. In Edwards $v$ California University at Pennsylvania, a federal court ruled against a professor who was pushing his religious beliefs on students during lectures. The ruling held that the university could control course content, concluding that the First Amendment does not give a public university professor the right to use curricula or teaching techniques that conflict with institutional requirements. ${ }^{10,11}$ 


\section{American Journal of Pharmaceutical Education 2016; 80 (9) Article 146.}

In another case, Hetrick $v$ Martin, a nontenured teacher's contract was not renewed because her teaching methods did not conform to those approved by the university. The decision was upheld on the basis that the First Amendment does not require a university or school to tolerate any manner of teaching method the teacher may choose to employ. ${ }^{10,12}$ Finally, in Urofsky $v$ Gilmore, a federal appeals court ruled against faculty members who challenged a Virginia statue requiring state employees to get prior written permission before accessing information "having sexually explicit content" using state-owned computers. The court ruled that academic freedom is historically an institutional right and that faculty members who do this type of research do not possess any greater rights than the general public. ${ }^{10,13}$ That is, academic freedom has not protected faculty members in cases involving abandonment of job responsibilities, lack of accountability, or failure to follow institutional policy. It is the responsibility of institutions and stakeholders to not allow faculty members to hide behind the false shield of academic freedom as an excuse to not be accountable in their jobs or not meet performance expectations. Such offensive behavior is not the fault of academic freedom but of all who tolerate it.

Undoubtedly, academic freedom is essential, and when invoked effectively and appropriately, it can optimize learning. Academic freedom ensures that both students and faculty members participate in the education process. Thus, faculty members and students must be given appropriate leeway to explore new ideas, new conceptual approaches, and new forms of argument and creativity as described in the original statement. ${ }^{3,14}$ If these allowances are not permitted, benefits to constituents (eg, the general public) will likely be dramatically reduced, thereby diminishing the overall principle for higher education to benefit the common good. ${ }^{3}$

Academic freedom does not conflict with shared governance; in fact, they go hand in hand. The 1940 Statement clearly supports the rights of the collective over individual rights. ${ }^{3}$ This is especially important in professional degree programs such as pharmacy that have professional and formal accreditation standards that govern curriculum and learning outcomes.

Curricular content, however, is the responsibility of the entire faculty. They must ensure that academic standards are appropriate and the prescribed learning outcomes are met. As stated in the 1999 AAUP Statement regarding academic freedom in medical schools, "decisions of the group may prevail over the dissenting position of a particular individual". ${ }^{6}$ Of great importance, academic freedom does not mean that unconditional protection for not performing in activities must be supported by supervisors, programs, departments, colleges or universities.

Arguments supporting redefinition of academic freedom include the issues of modernization of teaching environments, social media, the increasing number of nontenure faculty members, and changes to the economic climate. The fundamental concepts of academic freedom presented above remain valid in every "modern" scenario that faculty members face today; an example of this is provided in the 1999 Statement on Distance Education. ${ }^{7}$ The AAUP statement provides the backbone or "fundamentals" necessary to guide the institution (individual or global) regarding what faculty members are free to do. Institutions, however, should be responsible for developing procedures and policies to govern how faculty members carry out their duties. Because many of the examples mentioned (changes with tenure system, contract hires, use of social media, pedagogical changes) remain institution specific and change with time, it is imperative they be handled as "procedures" at the institutional level.

Similarly, the concept of academic freedom is independent of technological or pedagogical changes. For example, both academic freedom and the Hippocratic Oath are overarching principles that respectively guide faculty and physician behavior. Modern technology allows physicians to diagnose and treat patients from a distance, eg, via telehealth, yet the Hippocratic Oath has not been redefined. Physicians are still required to "do no harm" whether they care for a patient in person or not. Like the Hippocratic Oath, academic freedom guides what faculty members can do but does not address how they do it.

The 1970 Interpretive Comments on Academic Freedom state, "Both the protection of academic freedom and the requirements of academic responsibility apply not only to the full-time probationary and the tenured teacher, but also to all others, such as part-time faculty and teaching assistants, who exercise teaching responsibilities." The argument could be made that nontenure, contract employees have more security in terms of academic freedom, because the terms of their contract are negotiated. Concerns regarding evolution of faculty and tenure status and the decline in the number of tenured or tenure-track faculty members compared to the rising number of nontenured faculty members are valid. As the AAUP's 2009 Report on the Economic Status of the Profession points out, "the erosion of the tenure track rests on the fundamentally flawed premise" that faculty members "represent only a cost, rather than the institution's primary resource." 15 This report further points out that "hiring on the basis of the lower labor costs represents a disinvestment in the nation's intellectual capital precisely at the time when innovation and insight are most needed." 


\section{American Journal of Pharmaceutical Education 2016; 80 (9) Article 146.}

As evidenced by these comments, much more attention to the nature of faculty appointments in general is needed. Redefinition of academic freedom is not likely to resolve issues related to fiscal decision-making or types of faculty positions offered. As seen by the examples provided, the simplicity of The 1940 Statement of Academic Freedom has given it broad applicability across the academy as well as strength and validity over time.

\section{CONCLUSION}

This debate has brought into focus many issues surrounding academic freedom such as its ties to the tenure system, different types of teaching appointments, modernization of teaching environments, and changes in economic climate. That academic freedom is commonly misinterpreted is clear; however, whether academic freedom itself should be "redefined" is not clear. During the 2015 Debate session at the Interim AACP meeting, after hearing this debate, the question was posed to the audience, "Should academic freedom be redefined?" Overwhelmingly, the audience voted "no." Given the need for clarity regarding the scope of academic freedom in pharmacy education, we recommend that educational programming and perhaps a formal statement such as a white paper from the academy may encourage further discussion and may be the best approach to reaching a common understanding of academic freedom. Such a statement should address the issues brought out in this debate, eg, individual vs collective rights, tenure track and contingent faculty members, and changing teaching environments.

\section{REFERENCES}

1. Samuels WJ. The firing of E.A. Ross from Stanford University: injustice compounded by deception? J Econ Educ. 1991;22(2):183-190.
2. In 1954, the University of Michigan terminated Profs. Davis, Markert, and Nickerson for refusing to give testimony to the US House Committee on Un-American Activities. http://www.umich. edu/ aflf/background.html

3. Academic freedom and tenure. 1940 statement of principles. AAUP Bulletin. 1962;48(1):50-51. http:/www.jstor.org/stable/ 40223188.

4. Academic freedom and tenure: 1940 statement of principles and interpretive comments. AAUP Bulletin. 1970;56(3):323-326. http:// www.jstor.org/stable/40224269.

5. Van Alstyne WW. Academic freedom and the first amendment in the supreme court of the United States: an unhurried historical review. Law \& Contemp Probs. 1990;53(3):79-154.

6. Academic freedom in the medical school. Academe. 1999;85(4): 59-60. https://www.aaup.org/sites/default/files/academic-freedommedical-school.pdf.

7. Statement on Distance Education. American Association of University Professors website http://www.aaup.org/report/statementdistance-education. March 1999. Accessed August 13, 2015.

8. Is college worth it? The Economist. http://www.economist.com/ news/united-states/21600131-too-many-degrees-are-waste-moneyreturn-higher-education-would-be-much-better. Published April 5, 2014. Accessed May 3, 2015.

9. Schuster JH, Finkelstein MJ. The American Faculty: The Restructuring of Academic Work and Careers. Baltimore, MD: Johns Hopkins University Press; 2006:324.

10. Downs DA. Academic freedom. What it is, what it isn't, and how to tell the difference. Pope Center Series on Higher Education. http:// www.popecenter.org/acrobat/AcademicFreedom.pdf. May 2009.

Accessed January 30, 2016.

11. Edwards v California University of Pennsylvania, 156 F3d 488 (1998).

12. Hetrick $v$ Martin, $480 \mathrm{~F} 2 \mathrm{~d} 705\left(6^{\text {th }}\right.$ Cir 1973), at 709.

13. Urovsky v Gilmore, 216 F3d 401 (2000).

14. Franke AH. Academic freedom primer. Association of Governing Boards of Universities and Colleges website. http://agb. org/sites/default/files/legacy/u1525/Academic\%20Freedom $\%$ 20Primer.pdf. Accessed October 24, 2014.

15. Besosa M, Bousquet M, Barnes L, et al. Tenure and teachingintensive appointments. AAUP. 2010;96:89-100. http://search. proquest.com/docview $/ 762455695$ ?accountid $=14793$. 